\title{
Acupuncture and Moxibustion for Inflammatory Bowel Diseases: A Systematic Review and Meta-Analysis of Randomized Controlled Trials
}

\author{
Jun Ji, Yuan Lu, Huirong Liu, Hui Feng, Fuqing Zhang, Luyi Wu, \\ Yunhua Cui, and Huangan Wu
}

Key Laboratory for Acupuncture-Moxibustion and Immunological Effects, Shanghai University of Traditional Chinese Medicine, 650 South WanPing Road, Shanghai 200030, China

Correspondence should be addressed to Huangan Wu; wuhuangan@126.com

Received 8 June 2013; Revised 9 August 2013; Accepted 12 August 2013

Academic Editor: Yong-Qing Yang

Copyright (C) 2013 Jun Ji et al. This is an open access article distributed under the Creative Commons Attribution License, which permits unrestricted use, distribution, and reproduction in any medium, provided the original work is properly cited.

\begin{abstract}
Background. Inflammatory bowel diseases (IBD) are recurrent and refractory which include ulcerative colitis (UC) and Crohn's disease (CD). Clinical researches about acupuncture and moxibustion treatments for IBD are increasing, while systematic reviews about their efficacy remains in a shortage. This study sought to evaluate the efficacy of acupuncture and moxibustion for IBD. Methods. Seven significant databases both in and abroad were searched for randomized controlled trials (RCTs) which compared acupuncture and moxibustion as the main intervention to pharmacotherapy in treating IBD. A meta-analysis was performed. Results. A total of 43 RCTs were included. Among the 43 included trials, 10 trials compared oral sulphasalazine (SASP) with acupuncture and/or moxibustion treatments. A meta-analysis of the 10 trials indicated that acupuncture and moxibustion therapy was superior to oral SASP. Conclusion. Acupuncture and moxibustion therapy demonstrates better efficacy than oral SASP in treating IBD. However, given the limitations of this systematic review and the included literature, definitive conclusions regarding the exact efficacy of acupuncture and moxibustion treatment for IBD cannot be drawn. Extant RCTs still cannot provide sufficient evidence and multicentre, double-blind RCTs with large sample sizes are needed to provide higher-quality evidence.
\end{abstract}

\section{Introduction}

Inflammatory bowel diseases (IBD) encompass a group of chronic nonspecific inflammatory diseases of the bowel with unknown aetiology. The main forms of IBD are ulcerative colitis (UC) and Crohn's disease (CD). UC and CD are similar with regard to their clinical manifestations, diagnosis, and treatment. Clinically, both UC and CD involve the primary symptoms of abdominal pain and diarrhoea. These conditions are refractory and recurrent, causing high levels of patient suffering.

The aetiology and pathogenesis of IBD are not fully understood and, moreover, there is currently no specific treatment. The primary therapeutic approaches in clinical practice are derived from western medicine including traditional treatment with sulphasalazine (SASP; also known as 5-aminosalicyclic acid (5-ASA)) or the administration of steroids, immunosuppressive agents, or new biological agents. However, long-term treatment with steroids and immunosuppressants can cause serious adverse reactions, whereas new types of biological agents not only are expensive and economically burdensome to patients but also have unsatisfactory long-term efficacy.

Since the 1990s, there have been an increasing number of clinical studies of acupuncture and moxibustion treatment for IBD, and the existing investigations have demonstrated that acupuncture and moxibustion can effectively control bowel inflammation by providing multitargeted regulation of the body's physiological balance $[1,2]$. However, quality of these clinical studies is uneven, and types are varied. So far, systematic reviews or meta-analyses about acupuncture and moxibustion treatment for IBD are few. Therefore, it is necessary to conduct systematic evaluations and meta-analysis of randomized controlled trials (RCTs) of acupuncture and moxibustion in treating IBD. Also the studies could provide a reference for future clinical treatment and research. 


\section{Materials and Methods}

2.1. Search and Retrieval Strategy. Foreign-language and Chinese databases were searched. The Medline, Embase, and Cochrane Library databases were searched for Englishlanguage reports regarding RCTs. The Medline database was searched from 1966 to December 31, 2012, and Embase from 1974 to December 31, 2012. The Chinese literature databases that were searched include the China National Knowledge Infrastructure Database (CNKI), the Chongqing VIP Chinese Science and Technology Periodical Database (VIP), and the Chinese Biomedical Literature Database (CBM). The CNKI and CBM were searched to retrieve relevant studies from January 1, 1949, to December 31, 2012, whereas the VIP was searched to retrieve relevant studies from January 1, 1989, to December 31, 2012. The keywords used to for the Chinese-language literature include "inflammatory bowel diseases," "ulcerative colitis", "Crohn's disease", "acupuncture", "moxibustion", "acupoint”, and "acupuncture treatment"; the keywords used for English-language literature included "acupuncture", "moxibustion", "inflammatory bowel diseases" "ulcerative colitis", and "Crohn's disease" Based on the specific circumstances of the different databases, comprehensive searches for combinations of keywords and for wildcards were conducted to ensure the completeness of the search results.

2.2. Inclusion Criteria. (1) Research subjects: included studies were required to have enrolled patients with an unequivocal diagnosis of IBD (including UC and CD); no restrictions on race, age, or sex were imposed. (2) Study design: included studies were required to be RCTs in Chinese or English that evaluated the efficacy of acupuncture and/or moxibustion treatment for IBD. (3) Experimental group interventions: included studies were required to feature an experimental group that mainly received acupuncture and/or moxibustion treatment (including filiform needles, electroacupuncture, moxibustion, or cupping, among other techniques), either alone or in conjunction with other therapies (such as drug therapy), without differentiating among different acupuncture and moxibustion techniques, the selection of acupoints, or needle material. For studies in which the treatment group received acupuncture and/or moxibustion treatment combined with medication, the same drug had to be administered to both the treatment group and the control group. (4) Control group interventions: included studies were required to feature a control group that received medication, placebo, or sham acupuncture controlled treatment(s). (5) Outcome measurements: the outcome measurements of included studies had to include overall clinical efficacy, general conditions, changes in symptoms, serum inflammatory markers, and/or colonoscopic findings. (6) Availability: the full text or sufficiently informative abstracts of included studies had to be accessible.

2.3. Exclusion Criteria. The following types of studies were excluded from this analysis: (1) RCTs that lacked clear diagnostic criteria or basic information of the subjects or interventions; (2) serial observations, case reports, expert
TABLE 1: Modified Jadad quality scale.

\begin{tabular}{|c|c|c|}
\hline Aspects & Details & Score \\
\hline \multirow{3}{*}{ Randomization } & $\begin{array}{l}\text { Appropriate if random sequence is } \\
\text { generated by computer or similar } \\
\text { methods }\end{array}$ & 2 \\
\hline & $\begin{array}{l}\text { Unclear if a trial does not describe its } \\
\text { method of randomization }\end{array}$ & 1 \\
\hline & $\begin{array}{l}\text { Inappropriate if a study uses an } \\
\text { alternate assignment method, such as } \\
\text { the allocation of odd and even } \\
\text { numbers }\end{array}$ & 0 \\
\hline \multirow{4}{*}{$\begin{array}{l}\text { Randomization } \\
\text { concealment } \\
\text { colme }\end{array}$} & $\begin{array}{l}\text { Appropriate if either the distribution } \\
\text { scheme is controlled by a center or } \\
\text { pharmacy, containers with consistent } \\
\text { serial numbers being used, on-site } \\
\text { computer control, sealed opaque } \\
\text { envelopes, or any other allocation } \\
\text { method that clinicians and subjects are } \\
\text { unable to predict }\end{array}$ & 2 \\
\hline & $\begin{array}{l}\text { Unclear if only a random number table } \\
\text { or other random allocation scheme is } \\
\text { employed }\end{array}$ & 1 \\
\hline & $\begin{array}{l}\text { Inappropriate if either of alternate } \\
\text { allocation, case numbers, days of the } \\
\text { week, an open-label random number } \\
\text { table, serial coded envelopes, or any } \\
\text { other method with predictable } \\
\text { assignments is used }\end{array}$ & 0 \\
\hline & Absent if randomization is not used & 0 \\
\hline \multirow{3}{*}{$\begin{array}{l}\text { Blinding } \\
\text { method }\end{array}$} & $\begin{array}{l}\text { Appropriate if a completely identical } \\
\text { placebo form or a similar method is } \\
\text { used }\end{array}$ & 2 \\
\hline & $\begin{array}{l}\text { Unclear if the trial was described as } \\
\text { blinded, but no methodological } \\
\text { information regarding the blinding } \\
\text { was provided }\end{array}$ & 1 \\
\hline & $\begin{array}{l}\text { Inappropriate if the double-blind } \\
\text { method is not adopted or if the } \\
\text { blinding method is improper, such as a } \\
\text { comparison between tablets and } \\
\text { injections }\end{array}$ & 0 \\
\hline \multirow{2}{*}{$\begin{array}{l}\text { Withdrawal } \\
\text { and exit }\end{array}$} & $\begin{array}{l}\text { The number and reasons of patients } \\
\text { who withdraw or exit are described }\end{array}$ & 1 \\
\hline & $\begin{array}{l}\text { The number and reasons of patients } \\
\text { who withdraw or exit are not described }\end{array}$ & 0 \\
\hline
\end{tabular}

experiences, or descriptive analyses without control groups; (3) studies that compared different acupuncture and moxibustion techniques or selection of different acupoints to control groups; (4) studies that compared acupoint injections to drug therapy; (6) studies that were duplicate for retrieving or publishing.

2.4. Quality Assessments of the Included RCTs. The methodological quality of the included trials was evaluated using a modified Jadad quality scale (Table 1). The total possible 


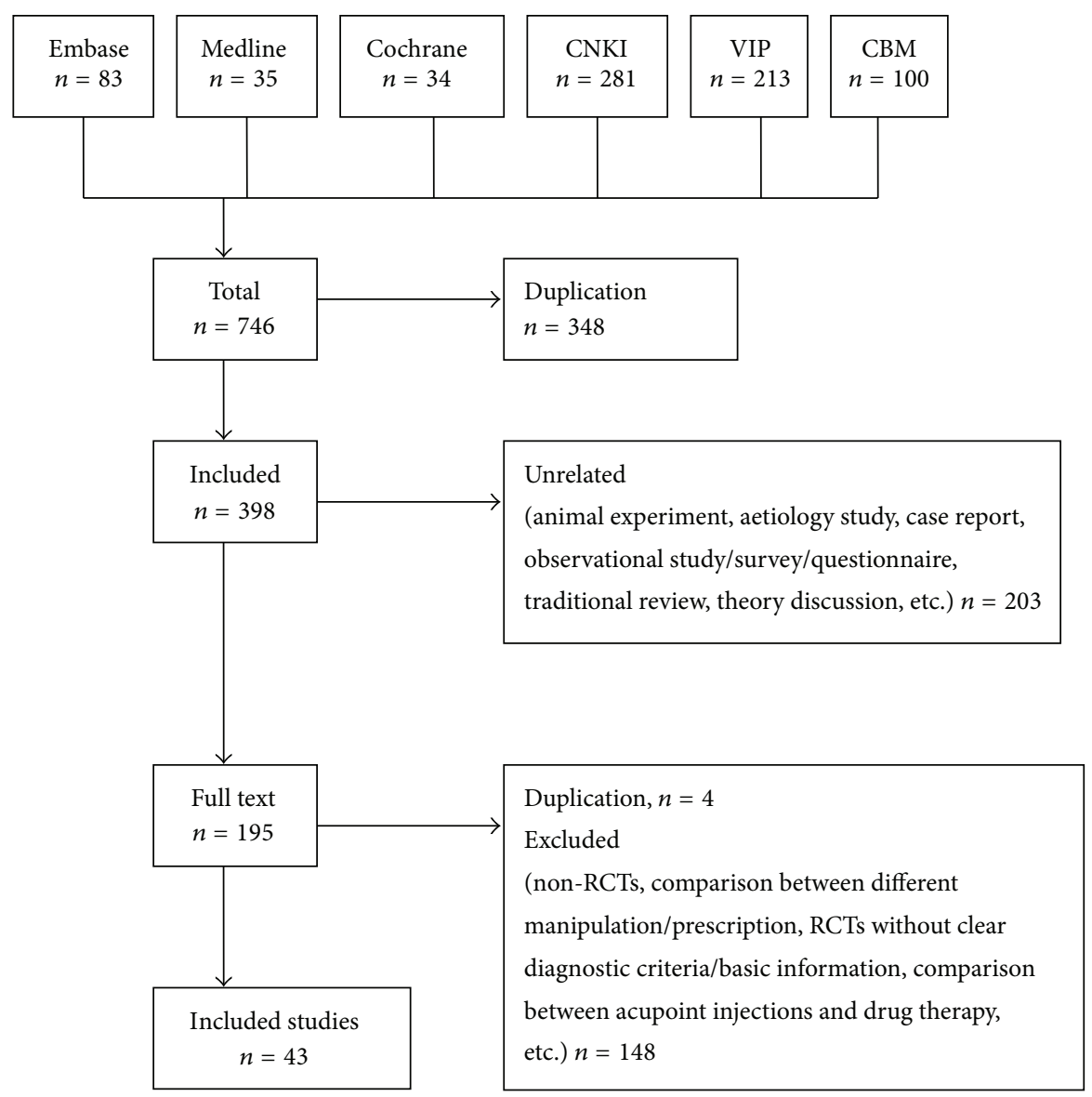

FIGURE 1: Flowchart of trial selection process. CNKI: China National Knowledge Infrastructure Database; VIP: Chongqing VIP Chinese Science and Technology Periodical Database; CBM: Chinese Biomedical Literature Database; RCT: randomized controlled trial.

score for study quality was 7 points. Studies with scores of 1-3 points were regarded as low-quality investigations, and studies with scores of 4-7 points were regarded as highquality investigations.

2.5. Data Retrieval. In accordance with the predetermined inclusion criteria, two researchers independently performed a rigorous screening to identify qualified trials, and they extracted data from these trials using a predesigned data extraction form independently. The extracted data included methodological features of the studies, demographic characteristics, treatment and control measurements, and primary outcome indicators. A third evaluator verified the consistency of the data, and any inconsistencies were addressed through discussion.

2.6. Data Analysis. The RevMan software package from the Cochrane Collaboration (Oxford, UK), version 5.1, was used for meta-analysis of the data. In the analysis of clinical efficacy, count data were assessed in terms of risk ratios (RRs), and continuous variables were assessed in terms of mean difference (MD). Both count data and continuous variables are expressed as efficacy values with $95 \%$ confidence intervals (CIs). If the meta-analysis results exhibited heterogeneity (defined as results of tests of heterogeneity that indicated that $P<0.1$ and $I^{2} \geq 50 \%$ ), then a random effects model will be used to assess combined efficacy values; otherwise, fixed effects models will be used for these assessments. Funnel plot analysis was used to evaluate the presence of publication bias.

\section{Results}

3.1. The Characteristics and Methodological Quality of the Included Trials. Using the search and retrieval strategy, a total of 746 studies were initially retrieved from the six aforementioned medical databases, including 152 English studies and 594 Chinese studies. The bibliographic information for these studies was imported into Microsoft Excel, and 348 duplicated titles were deleted. The titles and abstracts of the remaining studies were read to exclude irrelevant studies; after this process, 195 studies remained. These 195 studies were downloaded and full texts were read; using the predetermined exclusion criteria, 152 irrelevant studies were excluded. Finally, 43 studies were selected for inclusion [345], including 37 studies in Chinese and six studies in English. All of the included studies were published as journal articles. The flowchart for the literature search process is presented in Figure 1. 
Among the 43 included studies, there was one CD study [43] and 42 UC studies. These studies included a total of 4,021 patients with IBD; 2,146 of these patients were male (55.9\%), 1,691 were female $(44.1 \%)$, and the gender of the remaining 184 patients $(4.6 \%)$ was unknown because two studies did not report this information $[5,31]$. The average sample size of each included RCT was 93.5 and ranged from 29 to 640.

Acupuncture and moxibustion therapy was the main intervention in the treatment groups of the examined RCTs. These treatments primarily involved acupuncture and/or moxibustion, although certain studies examined acupoint catgut embedding therapy, acupoint application, and auricular acupressure. In particular, among the 43 included studies, acupuncture and moxibustion therapy was used as the intervention method for the treatment group in 17 studies [5, 8, 9, 13-19, 21, 23-25, 28, 36, 45]; moxibustion treatment was used as the main intervention in 12 studies $[5,8,9,13-19,28,36]$; acupuncture alone was used in one study [45]; acupoint catgut embedding therapy was used in two studies $[24,25]$; balance cupping therapy was used in one study [21]; and acupoint application was used in one study [23]. Comprehensive treatment, using two forms of therapy as an intervention method, was used in 19 studies $[3,6,7,12,20,22,26,27,29,31,33,35,37,39-44]$; in particular, combinations of two types of acupuncture and moxibustion treatments were used in 10 studies [3, 12, $22,29,35,37,41-44]$; a combination of acupuncture and moxibustion with SASP treatments was used in three studies $[6,20,39]$; a combination of acupuncture and moxibustion with Chinese herbal treatments was used in one study [40]; and a combination of acupuncture and moxibustion with a retention enema, using traditional Chinese medicine, was used in five studies [7, 26, 27, 31, 33]. A combination of three treatments was used as an intervention method in a total of six studies $[4,10,30,32,34,38]$; in particular, a combination of three types of acupuncture and moxibustion techniques was used in one study [38]; a combination of two types of acupuncture and moxibustion techniques and a retention enema using traditional Chinese medicine and/or western drugs was used in two studies [32,34]; a combination of two types of acupuncture and moxibustion techniques with Chinese herbal medicine was used in one study [4]; and a combination therapy of two types of acupuncture and moxibustion techniques with oral western medicine was used in two studies $[10,30]$. In addition, a combination of four interventions, including auricular acupressure, oral Chinese medicine, oral western medicine, and an enema with traditional Chinese medicine, was used in one study [11]. The interventions for the control groups consisted of drug therapy; in particular, most of these studies involved a control group that was administered SASP (27 studies). In addition, sham acupuncture was used as a control in two studies $[41,43]$.

The main outcome indicators reported in the included studies were overall efficacy, colonic activity indices, clinical symptom scores, fibre colonoscopy results, laboratory test findings (including evaluations of $\mathrm{T}$ lymphocyte subpopulations and immunoglobulin), and adverse reactions to treatments. The general data and methodological quality of the included studies are presented in Table 2, and the interventions and outcome measurements are presented in Table 3.

The assessments for bias risk revealed that among the 43 RCTs included in this systematic evaluation, nine RCTs reported their random allocation methods $[10-12,18,25,29$, $40,41,43]$, three studies utilized appropriate allocation concealment $[10,41,43]$, and the random allocation methods and allocation concealment of the remaining trials were either inappropriate or unclear. One study reported using a singleblind approach [41], one study addressed its implementation of a single-blind design and the reasons underlying the failure of final implementation [43], and unclear descriptions of blinding were provided in two trials [30, 37]. Two studies reported the numbers and the reasons of withdrawals from the trials $[41,43]$. One study utilised preliminary screening to estimate its sample size before its main experiments [41]. In general, the methodological and report qualities of the included studies were low. Four trials reported followup data [10, 22, 41, 43]. In particular, Zhou and Jin [10] reported that at the 1-year followup, the recurrence rate was significantly lower in the treatment group than in the control group $(P<0.05)$. Li et al. [22] observed that by the $2-$ year followup, 11 patients in the treatment group and 12 patients in the control group had experienced recurrences. In a 2004 CD study, Joos et al. [43] found that the efficacy was fundamentally maintained for 12 weeks of followup after treatment $(P=0.059)$, and the same research group reported in their 2006 UC study [41] that after 16-week follow-up, the primary outcome measurements remained more significantly improved than receiving treatment before $(P<0.001)$. The remaining included RCTs did not mention follow-up.

3.2. Results of Studies with High Jadad Scores. Three of the 43 included trials were of high quality $[10,41,43]$. Zhou and Jin [10] utilised an RCT to observe the efficacy in UC patients of electroacupuncture combined with ginger-partitioned moxibustion and oral SASP treatment. 220 patients in this trial were randomly divided into the treatment group ( $n=$ $110)$ and the SASP control group $(n=110)$; the overall clinical efficacy of the treatment group was $84.5 \%$, which was significantly better than the control treatment $(68.2 \%, P<$ 0.05). In a 2004 study of CD [43] and a 2006 study of UC [41], Joos et al. examined the treatment efficacy of acupuncture combined with moxibustion, with sham acupuncture (i.e., shallow punctures at non-acupoints) as a control, in investigations that featured the rigorous design and implementation of a prospective, randomized, controlled, single-blind trial (although the researchers reported that the implementation of the single-blind design was unsuccessful in their 2004 CD study). In the 2004 study, Joos et al. randomly divided $51 \mathrm{CD}$ patients into traditional Chinese medicine (TCM) group (acupuncture combined with moxibustion, $n=27$ ) and control group (sham acupuncture, $n=24$ ). After 4 weeks of treatment, the CD Activity Index (CDAI) of the patients in the TCM group had decreased significantly and was superior to the control group $(P=0.003)$. In their 2006 study, Joos et al. randomly divided 29 UC patients into TCM 
TABLE 2: Characteristics and methodological quality of included studies.

\begin{tabular}{|c|c|c|c|c|c|c|}
\hline Study & $\begin{array}{l}\text { Sample size } \\
\qquad\left(n_{1} / n_{2}\right)\end{array}$ & $\begin{array}{c}\text { Sex } \\
(\text { male/female })\end{array}$ & $\begin{array}{c}\text { Age } \\
\text { (mean or } \\
\text { range) }\end{array}$ & $\begin{array}{l}\text { Type of } \\
\text { IBD }\end{array}$ & Followup & $\begin{array}{r}\text { Methodology } \\
\text { quality score }\end{array}$ \\
\hline Ma and Zhang, 1997 [3] & $90(60 / 30)$ & $56 / 34$ & $\begin{array}{l}T: 23-68 \\
C: 28-65\end{array}$ & UC & No & 1 \\
\hline Gao, 1997 [4] & $66(46 / 20)$ & $27 / 39$ & $\begin{array}{l}T: 43.6 \\
C: 39.5\end{array}$ & UC & No & 1 \\
\hline Wu et al., 1999 [5] & $151(65 / 56 / 30)$ & $\mathrm{ND}$ & $\begin{array}{l}T: 42.7 \\
C: 38.4\end{array}$ & UC & No & 1 \\
\hline Li et al., 2008 [6] & $67(34 / 33)$ & $42 / 25$ & 35.5 & $\mathrm{UC}$ & No & 1 \\
\hline Mo et al., 2010 [7] & $62(31 / 31)$ & $35 / 27$ & 35.5 & UC & No & 1 \\
\hline $\begin{array}{l}\text { X. Guo and F. Guo, } 2010 \\
{[8]}\end{array}$ & $55(28 / 27)$ & $38 / 17$ & 38.77 & UC & No & 1 \\
\hline Yang et al., 2011 [9] & $100(50 / 50)$ & $61 / 39$ & $\begin{array}{l}T: 54.6 \\
C: 55.3\end{array}$ & UC & No & 1 \\
\hline Zhou and Jin, 2008 [10] & $220(110 / 110)$ & $131 / 89$ & $\begin{array}{l}T: 48.60 \\
C: 50.24\end{array}$ & UC & Yes & 4 \\
\hline Han et al., 2012 [11] & $81(41 / 40)$ & $47 / 34$ & $\begin{array}{l}T: 36.5 \\
C: 34.7\end{array}$ & UC & No & 1 \\
\hline Jiang, 2012 [12] & $80(40 / 40)$ & $39 / 41$ & $\begin{array}{l}T: 38.65 \\
C: 39.35\end{array}$ & UC & No & 3 \\
\hline Zhou, 2003 [13] & $66(34 / 32)$ & $31 / 35$ & 40.8 & UC & No & 1 \\
\hline Din et al., 2009 [14] & $61(30 / 31)$ & $32 / 29$ & $\begin{array}{l}T: 44.9 \\
C: 40.2\end{array}$ & $\mathrm{UC}$ & No & 1 \\
\hline Wu et al., 2000 [15] & $46(30 / 16)$ & $25 / 21$ & $\begin{array}{c}T: 38.75 \\
C: 37\end{array}$ & $\mathrm{UC}$ & No & 1 \\
\hline Wen, 2003 [16] & $69(39 / 30)$ & $35 / 34$ & $\begin{array}{l}T: 41.2 \\
C: 37.4\end{array}$ & UC & No & 1 \\
\hline Wang et al., 2006 [17] & $60(30 / 30)$ & $28 / 32$ & 38.5 & $\mathrm{UC}$ & No & 1 \\
\hline Xu et al., 2010 [18] & $60(28 / 32)$ & $35 / 25$ & $\begin{array}{l}T: 35.0 \\
C: 37.0\end{array}$ & $\mathrm{UC}$ & No & 2 \\
\hline Zhang, 2012 [19] & $60(30 / 30)$ & $32 / 28$ & $\begin{array}{l}T: 28-52 \\
C: 27-55\end{array}$ & UC & No & 1 \\
\hline Chi and Yu, 2011 [20] & $84(44 / 40)$ & $36 / 48$ & $\begin{array}{l}T: 45 \\
C: 43\end{array}$ & UC & No & 1 \\
\hline Luo, 2009 [21] & $76(40 / 36)$ & $42 / 34$ & $\begin{array}{l}T: 53 \\
C: 51.3\end{array}$ & $\mathrm{UC}$ & No & 1 \\
\hline Li et al., 2006 [22] & $68(40 / 28)$ & $40 / 28$ & $\begin{array}{l}T: 36.4 \\
C: 38.2\end{array}$ & UC & Yes & 1 \\
\hline Tian et al., 2012 [23] & $106(53 / 53)$ & $46 / 60$ & $\begin{array}{l}T: 29-61 ; \\
C: 32-63\end{array}$ & UC & No & 1 \\
\hline Chen, 2004 [24] & $130(100 / 30)$ & $80 / 50$ & $\begin{array}{l}T: 42.5 \\
C: 40.2\end{array}$ & UC & No & 1 \\
\hline Li et al., 2006 [25] & $116(56 / 60)$ & $52 / 64$ & $\begin{array}{l}T: 37.1 \\
C: 37.3\end{array}$ & UC & No & 2 \\
\hline Duan et al., 2012 [26] & $640(320 / 320)$ & $406 / 234$ & $\begin{array}{l}T: 45.5 \\
C: 46.5\end{array}$ & UC & No & 1 \\
\hline Sun and Wang, 1998 [27] & $88(45 / 43)$ & $43 / 45$ & $\begin{array}{l}T: 34.6 \\
C: 33.8\end{array}$ & UC & No & 1 \\
\hline Wang, 2008 [28] & $108(54 / 54)$ & $78 / 30$ & $\begin{array}{c}T: 35 \\
C: 33.5\end{array}$ & UC & No & 1 \\
\hline Ma and Xu, 2005 [29] & $92(47 / 45)$ & $51 / 41$ & $\begin{array}{l}T: 52.5 \\
C: 52.5\end{array}$ & UC & No & 2 \\
\hline Cui, 2010 [30] & $48(24 / 24)$ & $27 / 21$ & $\begin{array}{l}T: 43 \\
C: 44\end{array}$ & $\mathrm{UC}$ & No & 2 \\
\hline Guo et al., 2007 [31] & $33(22 / 11)$ & ND & ND & UC & No & 1 \\
\hline
\end{tabular}


TABLE 2: Continued.

\begin{tabular}{|c|c|c|c|c|c|c|}
\hline Study & $\begin{array}{l}\text { Sample size } \\
\qquad\left(n_{1} / n_{2}\right)\end{array}$ & $\begin{array}{c}\text { Sex } \\
\text { (male/female) }\end{array}$ & $\begin{array}{c}\text { Age } \\
\text { (mean or } \\
\text { range) }\end{array}$ & $\begin{array}{l}\text { Type of } \\
\text { IBD }\end{array}$ & Followup & $\begin{array}{l}\text { Methodology } \\
\text { quality score }\end{array}$ \\
\hline Wang et al., 2009 [32] & $78(39 / 39)$ & $44 / 34$ & $\begin{array}{l}T: 57.5 \\
C: 55.0\end{array}$ & UC & No & 1 \\
\hline Long and Yang, 2010 [33] & $46(23 / 23)$ & $20 / 26$ & $\begin{array}{l}T: 33.5 \\
C: 33.4\end{array}$ & UC & No & 1 \\
\hline Chen, 2010 [34] & $168(84 / 84)$ & $91 / 77$ & 38.4 & UC & No & 1 \\
\hline Sun and Wang, 2001 [35] & $55(35 / 20)$ & $32 / 23$ & $\begin{array}{l}T: 22-65 \\
C: 25-70\end{array}$ & UC & No & 1 \\
\hline Wang et al., 2006 [36] & $45(27 / 18)$ & $23 / 22$ & 40.5 & UC & No & 1 \\
\hline Shi et al., 2006 [37] & $60(30 / 30)$ & $34 / 26$ & $\begin{array}{l}T: 42.31 \\
C: 43.64\end{array}$ & UC & No & 2 \\
\hline Qun et al., 2012 [38] & $63(33 / 30)$ & $32 / 31$ & $\begin{array}{l}T: 46 \\
C: 41\end{array}$ & UC & No & 1 \\
\hline $\mathrm{Xu}, 2006$ [39] & $110(56 / 54)$ & $59 / 51$ & $\begin{array}{c}T: 35.5 \\
C: 33\end{array}$ & UC & No & 1 \\
\hline Zhang et al., 2011 [40] & $60(30 / 30)$ & $38 / 22$ & $\begin{array}{l}T: 31.2 \\
C: 30.6\end{array}$ & UC & No & 2 \\
\hline Joos et al., 2006 [41] & $29(15 / 14)$ & $10 / 19$ & $\begin{array}{c}37.89 \pm \\
12.0\end{array}$ & UC & Yes & 7 \\
\hline Yang and Yan, 1999 [42] & $62(32 / 30)$ & $30 / 32$ & $\begin{array}{l}T: 45.5 \\
C: 50.1\end{array}$ & UC & No & 1 \\
\hline Joos et al., 2004 [43] & $51(27 / 24)$ & $15 / 36$ & ND & $\mathrm{CD}$ & Yes & 5 \\
\hline Ma, 1999 [44] & $90(60 / 30)$ & $56 / 34$ & $\begin{array}{l}T: 23-68 \\
C: 28-65\end{array}$ & UC & No & 1 \\
\hline $\mathrm{Ma}, 2005$ [45] & $121(76 / 45)$ & $67 / 54$ & $\begin{array}{l}T: 42 \\
C: 41.5\end{array}$ & UC & No & 1 \\
\hline
\end{tabular}

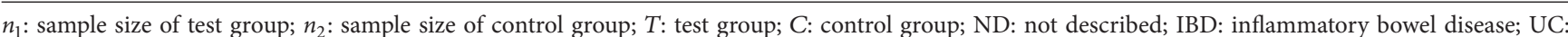
ulcerative colitis; CD: Crohn's disease.

group (acupuncture combined with moxibustion, $n=15$ ) and control group (sham acupuncture, $n=14$ ); after 5 weeks of treatment, the Colitis Activity Index (CAI) of the patients in the traditional Chinese medicine group was significantly lower than the CAI of the control group $(P=0.048)$.

3.3. Meta-Analysis Results. The 43 included RCTs featured complex interventions and different reported outcomes, with no unified efficacy standard. To develop a general understanding of the therapeutic effect of acupuncture and moxibustion therapy for IBD, intervention measurements and therapies for control group were further refined. We limited the treatment group methods to acupuncture or moxibustion alone, or a combination of acupuncture and moxibustion; this limitation produced 10 studies that compared one of the these treatments with oral SASP for the treatment of UC $[5,14-16,18,19,37,42,44,45]$. We then conducted a comprehensive efficacy evaluation of the interventions in the 10 RCTs, which featured simple interventions that could be readily compared with oral SASP. In addition, the efficacy criteria for these RCTs were similar, featuring the three outcomes of recently cured, effective, and ineffective; judgements of these outcomes were based on various indicators, such as clinical manifestations, routine stool test results, and colonoscopy findings. The definition of ineffective treatment was consistent among these 10 studies; therefore, a metaanalysis of the overall clinical efficacies determined in these studies could be performed.

3.3.1. Analysis of Overall Clinical Efficacy. The results of heterogeneity tests indicated that $I^{2}<50 \%$ and $P>0.1$ for the 10 examined studies and that the overall heterogeneity of subgroups was small $\left(P=0.28, I^{2}=17 \%\right)$; therefore, a fixed effects model was used. The overall efficacy of acupuncture alone, moxibustion alone, or acupuncture combined with moxibustion was greater than the efficacy of western medicine (oral SASP) for the treatment of IBD $(P<0.00001$, $\mathrm{RR}=5.42,95 \% \mathrm{CI}[3.38,8.68]$ ) (Figure 2 ).

3.4. Funnel Plot. RevMan, version 5.1, was used to conduct a funnel plot analysis of the aforementioned 10 studies, and the resulting graph was symmetrical, suggesting that these studies demonstrated no obvious publication bias (Figure 3 ).

\section{Discussion}

4.1. Methodological Quality of the Included Trials. Based on the RCTs examined in this study, the methodological quality of the clinical trials regarding the examined topic was 
TABLE 3: Interventions and outcomes of included studies.

\begin{tabular}{|c|c|c|c|}
\hline Study & Intervention & Control & Outcome measurement \\
\hline Ma and Zhang, 1997 [3] & $\begin{array}{l}\text { Acupuncture + sparrow-pecking } \\
\text { moxibustion }\end{array}$ & SASP + metronidazole & Efficacy \\
\hline Gao, $1997[4]$ & $\begin{array}{l}\text { Acupoint application }+ \text { moxibustion }+ \\
\text { decoction of traditional Chinese } \\
\text { medicine }\end{array}$ & Traditional Chinese medicine & Efficacy \\
\hline Wu et al., 1999 [5] & Drug-separated moxibustion & SASP & $\begin{array}{c}\text { Efficacy, T lymphocyte } \\
\text { subpopulations, HLA-DR } \\
\text { antigen }\end{array}$ \\
\hline Li et al., 2008 [6] & Moxa-box moxibustion + SASP & SASP & $\begin{array}{l}\text { Efficacy, haemorheology, } \\
\text { immunoglobulin, T lymphocyte } \\
\text { subpopulations }\end{array}$ \\
\hline Mo et al., 2010 [7] & $\begin{array}{l}\text { Moxa-box moxibustion }+ \text { traditional } \\
\text { Chinese medicine enema }\end{array}$ & $\begin{array}{l}\text { Traditional Chinese medicine } \\
\text { enema }\end{array}$ & Efficacy \\
\hline X. Guo and F. Guo, 2010 [8] & Warm moxibustion of acupoints & $\mathrm{SASP}+\mathrm{PAT}$ & $\begin{array}{l}\text { Efficacy, T lymphocyte } \\
\text { subpopulations }\end{array}$ \\
\hline Yang et al., 2011 [9] & Ginger moxibustion & Diphenoxylate & Efficacy \\
\hline Zhou and Jin, 2008 [10] & $\begin{array}{l}\text { Electroacupuncture + ginger } \\
\text { moxibustion + SASP }\end{array}$ & SASP & $\begin{array}{l}\text { Medical condition, efficacy, } \\
\text { intestinal mucosa pathology, } \\
\text { adverse reactions }\end{array}$ \\
\hline Han et al., 2012 [11] & $\begin{array}{l}\text { Auricular acupressure }+ \text { salicylic acid } \\
\text { preparations }+ \text { traditional Chinese } \\
\text { medicine }+ \text { traditional Chinese } \\
\text { medicine enema }\end{array}$ & $\begin{array}{c}\text { Salicylic acid preparations }+ \\
\text { traditional Chinese medicine }+ \\
\text { traditional Chinese medicine } \\
\text { enema }\end{array}$ & Enema retention time, efficacy \\
\hline Jiang, 2012 [12] & $\begin{array}{l}\text { Abdominal acupuncture }+ \text { acupoint } \\
\text { catgut embedding }\end{array}$ & Bupi Yichang pills & $\begin{array}{l}\text { Symptom scores, efficacy, fibre } \\
\text { colonoscopy }\end{array}$ \\
\hline Zhou, 2003 [13] & Ginger moxibustion & SASP + prednisone tablets & Efficacy \\
\hline Din et al., 2009 [14] & Ginger moxibustion & SASP & Efficacy \\
\hline Wu et al., 2000 [15] & $\begin{array}{l}\text { Moxibustion with herbal medicine } \\
\text { underneath }\end{array}$ & SASP & $\begin{array}{l}\text { Efficacy, colonic mucosal } \\
\text { histopathology, mucin }\end{array}$ \\
\hline Wen, 2003 [16] & Drug-separated moxibustion & SASP & Efficacy, immunoglobulin \\
\hline Wang et al., 2006 [17] & Drug-separated moxibustion & SASP + metronidazole tablets & $\begin{array}{c}\text { Efficacy, immunoglobulin, } \mathrm{T} \\
\text { lymphocyte subpopulations, NK } \\
\text { content }\end{array}$ \\
\hline Xu et al., 2010 [18] & Herb-partitioned moxibustion & SASP & Efficacy, adverse reactions \\
\hline Zhang, 2012 [19] & Drug-separated moxibustion & SASP & Efficacy \\
\hline Chi and Yu, $2011[20]$ & $\begin{array}{l}\text { Umbilical compression with } \\
\text { traditional Chinese medicine + SASP }\end{array}$ & SASP & Efficacy \\
\hline Luo, 2009 [21] & Balance cupping & Enteritidis tablet & $\begin{array}{l}\text { Efficacy, symptom scores, } \\
\text { immunoglobulin }\end{array}$ \\
\hline Li et al., 2006 [22] & $\begin{array}{l}\text { Application of musky warm umbilical } \\
\text { cream }+ \text { use of a specific } \\
\text { electromagnetic spectrum therapeutic } \\
\text { apparatus }\end{array}$ & SASP & Efficacy \\
\hline Tian et al., 2012 [23] & Acupoint application & SASP & Efficacy, symptom scores \\
\hline Chen, 2004 [24] & Acupoint catgut embedding & SASP & Efficacy \\
\hline Li et al., 2006 [25] & Acupoint catgut embedding & SASP & $\begin{array}{l}\text { Efficacy, stool characteristics, } \\
\text { abdominal pain }\end{array}$ \\
\hline Duan et al., 2012 [26] & $\begin{array}{l}\text { Acupoint catgut embedding }+ \\
\text { traditional Chinese medicine enema }\end{array}$ & $\begin{array}{c}\text { Traditional Chinese medicine } \\
\text { enema }\end{array}$ & Efficacy, routine stool tests \\
\hline Sun and Wang, 1998 [27] & $\begin{array}{l}\text { Warm acupuncture }+ \text { traditional } \\
\text { Chinese medicine enema }\end{array}$ & $\begin{array}{l}\text { Traditional Chinese medicine } \\
\text { enema }\end{array}$ & Efficacy \\
\hline Wang, 2008 [28] & Warm acupuncture & SASP + western medicine enema & Efficacy \\
\hline
\end{tabular}


TABLE 3: Continued.

\begin{tabular}{|c|c|c|c|}
\hline Study & Intervention & Control & Outcome measurement \\
\hline $\mathrm{Ma}$ and $\mathrm{Xu}, 2005$ [29] & Acupuncture + TDP & SASP & Efficacy \\
\hline Cui, $2010[30]$ & Acupuncture + moxibustion + SASP & SASP & $\begin{array}{c}\text { Efficacy, serum levels of TNF- } \alpha \text {, } \\
\text { IL-1, and IL-10 }\end{array}$ \\
\hline Guo et al., 2007 [31] & $\begin{array}{l}\text { Acupuncture }+ \text { traditional Chinese } \\
\text { medicine enema }\end{array}$ & $\begin{array}{c}\text { Traditional Chinese medicine } \\
\text { enema }\end{array}$ & Efficacy, intestinal microscopy \\
\hline Wang et al., 2009 [32] & $\begin{array}{l}\text { Electroacupuncture }+ \text { ginger } \\
\text { moxibustion }+ \text { traditional Chinese and } \\
\text { western medicine enema }\end{array}$ & $\begin{array}{l}\text { Traditional Chinese and western } \\
\text { medicine enema }\end{array}$ & Efficacy \\
\hline Long and Yang, 2010 [33] & $\begin{array}{l}\text { Acupuncture }+ \text { traditional Chinese } \\
\text { medicine enema }\end{array}$ & $\begin{array}{c}\text { Traditional Chinese medicine } \\
\text { enema }\end{array}$ & Efficacy, colonoscopy \\
\hline Chen, 2010 [34] & $\begin{array}{l}\text { Acupuncture }+ \text { ginger moxibustion }+ \\
\text { traditional Chinese medicine enema }\end{array}$ & $\begin{array}{c}\text { Traditional Chinese medicine } \\
\text { enema }\end{array}$ & Efficacy \\
\hline Sun and Wang, 2001 [35] & Acupuncture + ginger moxibustion & $\begin{array}{l}\text { Shuanghuanglian compound + } \\
\text { norfloxacin + gentamicin }\end{array}$ & Efficacy \\
\hline Wang et al., 2006 [36] & Warm acupuncture & SASP & Efficacy \\
\hline Shi et al., 2006 [37] & Electroacupuncture + moxibustion & SASP & $\begin{array}{c}\text { Efficacy, serum levels of TNF- } \alpha \text {, } \\
\text { IL- } 8 \text {, IL-1, and IL-10 }\end{array}$ \\
\hline Qun et al., 2012 [38] & Acupuncture + moxibustion + TDP & SASP & $\begin{array}{l}\text { Efficacy, intestinal mucosa } \\
\text { pathology, immunoglobulin }\end{array}$ \\
\hline $\mathrm{Xu}, 2006$ [39] & Ginger moxibustion + SASP & SASP & Efficacy \\
\hline Zhang et al., 2011 [40] & $\begin{array}{l}\text { Traditional acupuncture }+ \text { Chinese } \\
\text { medicine decoction }\end{array}$ & SASP & $\begin{array}{l}\text { Efficacy, symptom scores, serum } \\
\text { levels of IL-8 and IL-10 }\end{array}$ \\
\hline Joos et al., 2006 [41] & $\begin{array}{l}\text { Traditional acupuncture }+ \\
\text { moxibustion }\end{array}$ & Sham acupuncture & $\begin{array}{l}\text { CAI, QLO, general well-being, } \\
\text { C-reactive protein, serum } \alpha_{1} \text {-acid } \\
\text { glycoprotein }\end{array}$ \\
\hline Yang and Yan, 1999 [42] & Acupuncture + moxibustion & SASP & $\begin{array}{c}\text { Efficacy, routine examination of } \\
\text { faeces, electrogastrograms, } \\
\text { sigmoidoscopy }\end{array}$ \\
\hline Joos et al., 2004 [43] & $\begin{array}{l}\text { Traditional acupuncture }+ \\
\text { moxibustion }\end{array}$ & Sham acupuncture & $\begin{array}{l}\text { CDAI, QLO, general condition, } \\
\text { C-reactive protein, serum } \alpha_{1} \text {-acid } \\
\text { glycoprotein }\end{array}$ \\
\hline Ma, $1999[44]$ & $\begin{array}{l}\text { Acupuncture }+ \text { sparrow-pecking } \\
\text { moxibustion }\end{array}$ & SASP & Efficacy \\
\hline $\mathrm{Ma}, 2005[45]$ & Acupuncture & SASP & Efficacy \\
\hline
\end{tabular}

SASP: sulphasalazine; IBDQ: Inflammatory Bowel Disease Questionnaire; CAI: Colitis Activity Index; QOL: quality of life; CDAI: Crohn's Disease Activity Index; PAT: pipemidic acid tablet; sham acupuncture: superficial needling at nonacupoints.

generally low, and few studies provided robust evidence. Randomization and allocation concealment are among the ways in which bias can arise, and the vast majority of the examined trials only mentioned "randomization", without describing the specific methods used or whether allocation concealment was implemented. Thus, nonstandard "randomization" was widespread. The selective reporting of research results or the loss of trial data can also lead to reporting bias. Among the 43 included trials, only two studies reported the numbers of withdrawals from the study and the reasons; because none of the other trials reported exit data or cases lost to followup, the efficacy conclusions of these trials might be exaggerated. Most of the studies did not utilize blinding, producing a high probability of bias. The overall quality of the studies was low, affecting the strength of the evidence that was examined in this systematic evaluation.
4.2. Determinations of Sample Size. Adequate attention must be devoted to the important factor of sample size in RCTs that address the examined topic. At present, only two relevant RCTs have featured sample sizes of more than 200 individuals. Insufficient sample sizes can reduce the power of a test, resulting in limited reliability of the results and conclusions, that do not truly reflect the overall effects observed in a study. Low statistical power will reduce the magnitude of evidence that RCTs can provide.

4.3. Selection of Interventions. In this study, the specific interventions described in the included studies, which included acupuncture, herb-partitioned moxibustion, gingerpartitioned moxibustion, moxibustion, electroacupuncture, abdominal acupuncture, acupuncture catgut embedding, acupoint application, cupping, and auricular pressure, were 


\begin{tabular}{|c|c|c|c|c|c|c|c|c|c|c|}
\hline \multirow{2}{*}{ Study or subgroup } & \multicolumn{2}{|c|}{ Treatment } & \multicolumn{2}{|c|}{ Control } & \multirow{2}{*}{ Weight } & \multirow{2}{*}{\multicolumn{2}{|c|}{$\begin{array}{c}\text { Odds ratio } \\
\text { M-H, fixed, } 95 \% \text { CI }\end{array}$}} & \multirow{2}{*}{\multicolumn{2}{|c|}{$\begin{array}{c}\text { Odds ratio } \\
\mathrm{M}-\mathrm{H} \text {, fixed, } 95 \% \mathrm{CI}\end{array}$}} & \\
\hline & Events & Total & Events & Total & & & & & & \\
\hline Ding H 2009 [14] & 30 & 30 & 28 & 31 & $3.0 \%$ & $7.49[0.37,151.50]$ & & & & $\rightarrow$ \\
\hline Ma S 1999 [44] & 58 & 60 & 25 & 30 & $7.3 \%$ & $5.80[1.05,31.93]$ & & & & \\
\hline Ma X 2005 [45] & 73 & 76 & 22 & 45 & $7.2 \%$ & $25.44[6.97,92.80]$ & & & & \\
\hline Wang SM 2003 [36] & 24 & 27 & 15 & 18 & $13.2 \%$ & $1.60[0.28,8.98]$ & & & 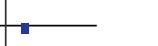 & \\
\hline Wen LJ 2003 [16] & 35 & 39 & 12 & 16 & $11.5 \%$ & $2.92[0.63,13.51]$ & & & & \\
\hline Wu HG 1999 [5] & 110 & 121 & 20 & 30 & $19.2 \%$ & $5.00[1.88,13.32]$ & & & & \\
\hline Wu HG 2000 [15] & 29 & 30 & 12 & 16 & $3.4 \%$ & $9.67[0.98,95.67]$ & & & & \\
\hline Xu YL 2010 [18] & 25 & 28 & 25 & 32 & $16.5 \%$ & $2.33[0.54,10.06]$ & & & - & \\
\hline Yang C 1999 [42] & 31 & 32 & 29 & 30 & $6.2 \%$ & $1.07[0.06,17.89]$ & & & & \\
\hline Zhang HP 2012 [19] & 27 & 30 & 19 & 30 & $12.5 \%$ & $5.21[1.28,21.24]$ & & & & \\
\hline Total $(95 \% \mathrm{CI})$ & & 473 & & 278 & $100.0 \%$ & $5.42[3.38,8.68]$ & & & & \\
\hline Total events & 442 & & 207 & & & & & & & \\
\hline \multirow{2}{*}{\multicolumn{7}{|c|}{$\begin{array}{l}\text { Heterogeneity: } \chi^{2}=10.91, \mathrm{df}=9(P=0.28), I^{2}=17 \% \\
\text { Test for overall effect: } Z=7.03(P<0.00001)\end{array}$}} & 0.01 & 0.1 & 10 & 100 \\
\hline & & & & & & & & $\begin{array}{l}\text { Favors } \\
\text { perimental }\end{array}$ & $\begin{array}{l}\text { Favors } \\
\text { control }\end{array}$ & \\
\hline
\end{tabular}

FIGURE 2: Forest plot of acupuncture and/or moxibustion for ulcerative colitis Compared to SASP.

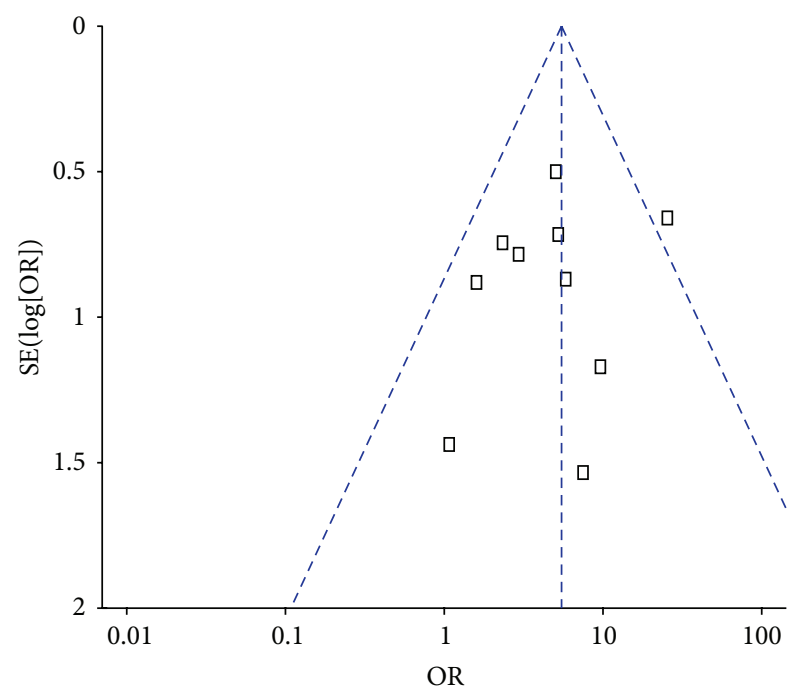

FIGURE 3: Funnel plot of randomized controlled trials using acupuncture and/or moxibustion for ulcerative colitis.

treated as one type of therapy, without considering the differences in acupoint selection or therapeutic techniques. Therefore, the results of this study might indicate overall efficacy trends, but they cannot be utilised to draw definitive conclusions, thus limiting the extent to which the conclusions of this investigation can be applied.

4.4. The Selection and Measurement of Outcome Indicators. The majority of the included studies selected clinical efficacy as the outcome measurement. Thus, there may exist subjectivity in the evaluations of the results. With little use of objective indicators, such as clinical symptom scores, endoscopic scores, or pathologic scores, the tendency towards subjective judgements weakened the credibility of conclusions regarding the effectiveness of acupuncture and moxibustion. With regard to long-term efficacy, most of the included studies did not conduct long-term followup, or if someone did, either the data for withdraw or the followup methods were not described. As a result, the long-term efficacy of acupuncture and moxibustion treatment for IBD cannot be determined.

4.5. Suggestions for Future Research. The objectivity and accuracy of systematic evaluations rely on high-quality RCTs. The findings of this systematic evaluation are somewhat limited due to the generally low quality of the existing studies. Thus, it is recommended that future research should be based on the Consolidated Standards of Reporting Trials (CONSORT) statement [46]. In particular, future studies should provide detailed reports regarding the generation of random allocation sequences and allocation concealment; moreover, to the greatest possible extent, these studies should be blinded and placebo controlled. In addition, a subject flowchart should be utilised to provide detailed accounts of patient withdrawals and loss during trials. Followup should be strengthened, and all of the trial data should be completely reported. In addition, intent-to-treat analysis should be conducted to evaluate therapeutic effects. These measurements will produce clinical RCTs that provide high levels of reliable evidence.

\section{Conclusion}

The results of this study suggest that acupuncture and moxibustion treatment demonstrated better overall efficacy than oral SASP in treating IBD. However, given the limitations of 
this systematic evaluation and the included studies, definitive conclusions cannot be drawn with regard to the specific efficacy of acupuncture and moxibustion treatment for IBD. Currently published RCTs have not provided sufficient evidence for the effectiveness of acupuncture and moxibustion for IBD; thus, multicentre, double-blind RCTs with large sample sizes are still required to provide higher levels of evidence.

\section{Conflict of Interests}

The authors of this paper state that they have no conflict of interests associated with this investigation.

\section{Authors' Contribution}

Jun Ji, Yuan Lu, and Huirong Liu contributed equally to this work.

\section{Acknowledgments}

This study was financially supported by grants from the 973 Program of China (no. 2009CB522900), National Natural Science Foundation of China (no. 81173331), and Shanghai Municipal Health Bureau (no. 20124028; no. 2010QL025B).

\section{References}

[1] H. G. Wu, B. M. Zhang, and G. Q. An, "Herb-partitioned moxibustion modulates ulcerative colitis fibrosis TGF- $\beta$ and its receptorsin rats," Journal of Jiangxi College of Traditional Chinese Medicine, vol. 15, no. 1, pp. 39-42, 2003.

[2] H. G. Wu, L. B. Zhou, C. Huang et al., "Discussion about cytokine gene expression modulated by acupuncture and moxibustion treatment of ulcerative colitis in rats," The Chinese Journal of Gastroenterology, vol. 6, no. 10, pp. 853-855, 1998.

[3] S. Ma and G. L. Zhang, "Efficacy of acupuncture and moxibustion treatment in 60 cases of ulcerative colitis," Chinese Acupuncture and Moxibustion, vol. 17, no. 5, pp. 275-276, 1997.

[4] Y. Gao, "Clinical observations of 46 cases of ulcerative colitis treated by medication combined with moxibustion," Journal of Sichuan Continuing Education College of Medical Sciences, vol. 16, no. 3, pp. 152-153, 1997.

[5] H. G. Wu, W. L. Tan, H. P. Chen et al., "The efficacy of moxibustion treatment of ulcerative colitis and the impact of the HLA-DR antigen on intestinal epithelial cells," Acupuncture Research, vol. 24, no. 1, pp. 12-16, 1999.

[6] H. Q. Li, Y. Zhou, D. Q. Zhang et al., "Effect of moxibustion in box in Shenque, Shangjuxu and Xiajuxu acupoints for chronic ulcerative colitis," Clinical Acupuncture and Moxibustion, vol. 24, no. 9, pp. 33-35, 2008.

[7] Y. X. Mo, X. F. Wang, W. R. Qu et al., "Observation on curative effect of moxa box moxibustion plus Chinese herbal medicine enema to treat patients with chronic ulcerative colitis," Chinese Nursing Research, vol. 24, no. 1, pp. 216-217, 2010.

[8] X. Guo and F. Guo, "The moxibustion of heat-sensitive acupoints as a therapy for ulcerative colitis," China's Naturopathy, vol. 18 , no. 2, p. 12, 2010.
[9] H. J. Yang, Q. L. Zhao, and S. G. Zhao, "Efficacy of moxibustion at the Shenque acupoint for the treatment of 50 cases of chronic colitis," Journal of Qilu Nursing, vol. 17, no. 34, p. 125, 2011.

[10] G. Y. Zhou and J. H. Jin, "Effect of electroacupuncture plus moxibustion combined with medicine on ulcerative colitis," Chinese Archives of Traditional Chinese Medicine, vol. 26, no. 9, pp. 2069-2071, 2008.

[11] S. H. Han, Z. H. Xu, X. F. Chen et al., "Efficacy observation of seeds buried at ear acupuncture point in combined with traditional Chinese medicine enema for the treatment of ulcerative colitis," Nursing and Rehabilitation Journal, vol. 11, no. 6, pp. 570-571, 2012.

[12] X. P. Jiang, "Efficacy of treating ulcerative colitis by abdominal acupuncture plus catgut embedding," Clinical Journal of Chinese Medicine, vol. 4, no. 17, pp. 37-39, 2012.

[13] J. H. Zhou, "Clinical observations of ginger-partitioned moxibustion in 34 cases of ulcerative colitis," Jiangsu Journal of Traditional Chinese Medicine, vol. 24, no. 10, pp. 44-45, 2003.

[14] H. Din, H. Wang, T. Zhang et al., "Effects of ginger-partitioned moxibustion on 30 patients with asdthenic splenonephro-yang of ulcerative colitis," Acta Academiae Medicinae CPAPF, vol. 18, no. 6, pp. 509-511, 2009.

[15] H. G. Wu, L. B. Zhou, D. R. Shi et al., "Morphological study on colonic pathology ulcerative colitis treated by moxibustion," World Journal of Gastroenterology, vol. 6, no. 6, pp. 861-865, 2000.

[16] L. J. Wen, "Clinical Observation of herb-partitioned in treating chronic ulcerative colitis," Journal of Jiangxi College of Traditional Chinese Medicine, vol. 15, no. 2, pp. 35-36, 2003.

[17] S. M. Wang, L. Q. Zhang, J. Sun et al., "The clinical efficacy of acupuncture and moxibustion for the treatment of ulcerative colitis," Practical Journal of Medicine and Pharmacy, vol. 20, no. 2, p. 135, 2003.

[18] Y. L. Xu, Y. H. Du, and X. M. Xu, "Effect of herb-partitioned spread moxibustion for the treatment of chronic ulcerative colitis," Chinese Acupuncture and Moxibustion, vol. 30, no. 4, pp. 289-291, 2010.

[19] H. P. Zhang, "Efficacy of herb cake-partitioned moxibustion in treating 60 cases of chronic ulcerative colitis," Nei Mongol Journal of Traditional Chinese Medicine, vol. 31, no. 7, p. 79, 2012.

[20] L. L. Chi and M. M. Yu, "Shenque acupoint application of a spleen-strengthening ulcer-healing preparation combined with sulfasalazine for the treatment of 44 cases of chronic ulcerative colitis," Journal of Practical Traditional Chinese Internal Medicine, vol. 25, no. 8, pp. 55-57, 2011.

[21] Y. H. Luo, "Balanced cupping treatment for 40 cases of ulcerative colitis," Jiangxi Journal of Traditional Chinese Medicine, vol. 40, no. 2, pp. 63-64, 2009.

[22] D. P. Li, Q. Chen, L. Yi et al., "The use of umbilical application of musky warm cream combined with electromagnetic wave irradiation for the treatment of 40 cases of ulcerative colitis," Shaanxi Journal of Traditional Chinese Medicine, vol. 27, no. 1, pp. 49-50, 2006.

[23] J. R. Tian, X. J. Li, H. W. Han et al., "Clinical observation of Shenque acupoint in treating chronic ulcerative colitis," Hebei Journal of Traditional Chinese Medicine, vol. 34, no. 6, pp. 884885, 2012.

[24] J. Chen, "Clinical observations of specific acupoint catgutembedding treatment for chronic ulcerative colitis," Journal of Sichuan of Traditional Chinese Medicine, vol. 22, no. 5, pp. 8990, 2004. 
[25] H.-J. Li, G.-P. Li, and H.-Y. Li, "Clinical observation on acupoint catgut embedding therapy for treatment of ulcerative colitis," Chinese Acupuncture and Moxibustion, vol. 26, no. 4, pp. 261263, 2006.

[26] D. J. Duan, L. N. Zhang, J. T. Yin et al., "Clinical observation of catgut embedding combined with Pulsatilla decoction enema for the treatment of chronic ulcerative colitis," Hebei Journal of Traditional Chinese Medicine, vol. 34, no. 5, pp. 721-722, 2012.

[27] Y. T. Sun and S. L. Wang, "Warm needle acupuncture combined with retention enema for the treatment of 45 cases of ulcerative colitis," Journal of Chinese Acupuncture and Moxibustion, vol. 9 , p. $562,1998$.

[28] S. L. Wang, "Efficacy of warm needle acupuncture for the treatment of ulcerative colitis," Journal of Chinese Community Doctors, vol. 10, no. 22, pp. 132-133, 2008.

[29] T. A. Ma and Z. K. Xu, "Efficacy of acupuncture plus TDP for the treatment of chronic ulcerative colitis," Central Plains Medical Journal, vol. 32, no. 17, pp. 31-32, 2005.

[30] J. Cui, "The impact of acupuncture treatment on the cytokines of patients with ulcerative colitis," Hebei Medical Journal, vol. 32, no. 11, pp. 1409-1410, 2010.

[31] X. Y. Guo, Z. J. Long, X. Wu et al., "Observations of the efficacy of acupuncture and moxibustion combined with Chinese medicine enema treatment for 22 cases of ulcerative colitis," Liaoning Journal of Traditional Chinese Medicine, vol. 34, no. 5, pp. 654-655, 2007.

[32] D. M. Wang, X. G. Zhang, K. Chen et al., "Acupuncture and moxibustion combined with Chinese and Western medicine retention enema to treat ulcerative colitis," Practical Pharmacy and Clinical Reme, vol. 12, no. 3, pp. 224-225, 2009.

[33] Z. J. Long and X. L. Yang, "Acupuncture and moxibustion combined with traditional Chinese medicine enema for the treatment of 23 cases of ulcerative colitis," Chinese Journal of Coloproctology, vol. 30, no. 2, pp. 58-59, 2010.

[34] H. Y. Chen, "Efficacy and care-related observations of acupuncture and moxibustion combined with traditional Chinese medicine enema for ulcerative colitis," Chinese and Foreign Medical Research, vol. 8, no. 12, pp. 101-102, 2010.

[35] G. H. Sun and X. L. Wang, "Acupuncture and moxibustion treatment of 35 cases of chronic ulcerative colitis," Journal of Practical Traditional Chinese Medicine, vol. 17, no. 6, p. 32, 2001.

[36] S. H. Wang, X. G. Li, L. Q. Zhang et al., "Clinical study on herb-partitioned moxibustion at Shenque (CV 8) acupiont for treatment of ulcerative colitis," Chinese Acupuncture and Moxibustion, vol. 26, no. 2, pp. 97-99, 2006.

[37] Y. Q. Shi, S. P. Liu, and J. G. Liu, "The impact of acupuncture and moxibustion treatment on cytokine levels in patients with ulcerative colitis," Hubei Journal of Traditional Chinese Medicine, vol. 28, no. 2, pp. 11-12, 2006.

[38] S. Qun, J. Lu, and S. M. Guo, "Efficacy of acupuncture and moxibustion at crossed points as main treatment for ulcerative colitis," Shanghai Journal of Acupuncture and Moxibustion, vol. 31, no. 5, pp. 319-320, 2012.

[39] Q. J. Xu, "Clinical observation of an integrated traditional and western treatment for 56 cases of chronic ulcerative colitis," Journal of Chinese Physician, vol. 34, no. 1, pp. 48-49, 2006.

[40] Z. J. Zhang, S. Xie, G. F. Ma et al., "The impact of traditional Chinese medicine on serum IL-8 and IL-10 levels of ulcerative colitis patients," Shaanxi Journal of Traditional Chinese Medicine, vol. 32, no. 5, pp. 566-568, 2011.
[41] S. Joos, N. Wildau, R. Kohnen et al., "Acupuncture and moxibustion in the treatment of ulcerative colitis: a randomized controlled study," Scandinavian Journal of Gastroenterology, vol. 41, no. 9, pp. 1056-1063, 2006.

[42] C. Yang and H. Yan, "Efficacy of acupuncture and moxibustion in 62 cases of chronic colitis," Journal of Traditional Chinese Medicine, vol. 19, no. 2, pp. 111-114, 1999.

[43] S. Joos, B. Brinkhaus, C. Maluche et al., "Acupuncture and moxibustion in the treatment of active Crohn's disease: a randomized controlled study," Digestion, vol. 69, no. 3, pp. 131139, 2004.

[44] S. Ma, "Observation on the therapeutic effect of combined treatment of 60 cases of ulcerative colitis with acupuncture and moxibustion," World Journal of Acupuncture-Moxibustion, vol. 9, no. 1, p. 24, 1999.

[45] X. Ma, "Acupuncture treatment for 76 cases of ulcerative colitis," Journal of Traditional Chinese Medicine, vol. 25, no. 4, pp. 264265, 2005.

[46] K. F. Schulz, D. G. Altman, and D. Moher, "CONSORT 2010 statement: updated guidelines for reporting parallel group randomized trials," Annals of Internal Medicine, vol. 152, no. 11, pp. 726-732, 2010. 


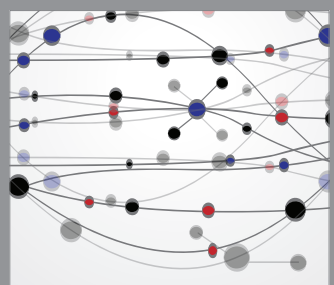

The Scientific World Journal
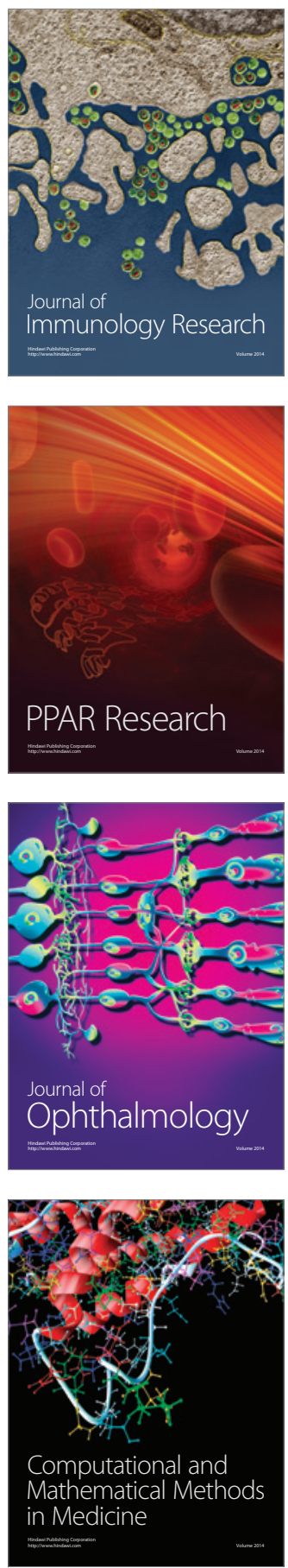

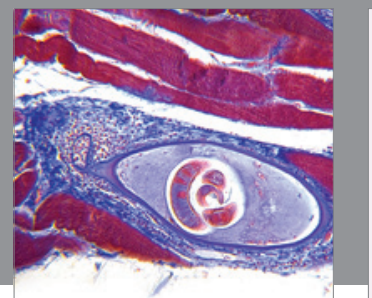

Gastroenterology

Research and Practice
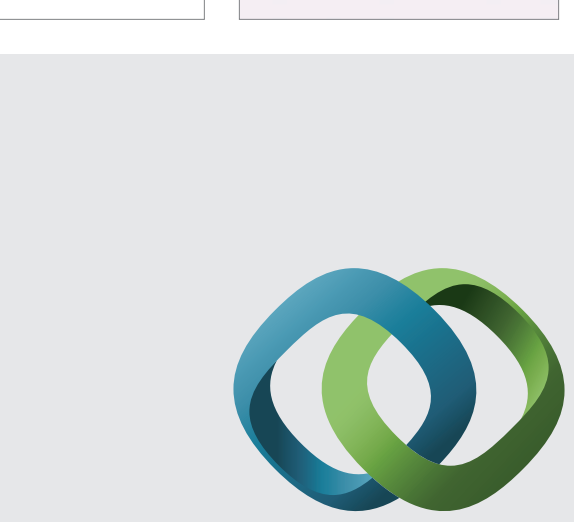

\section{Hindawi}

Submit your manuscripts at

http://www.hindawi.com
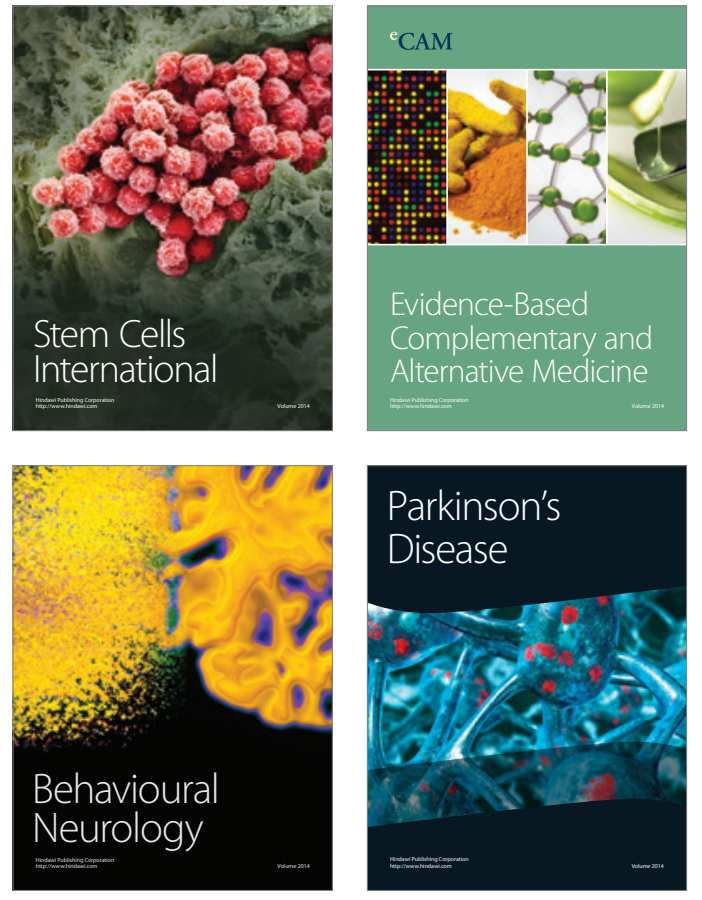
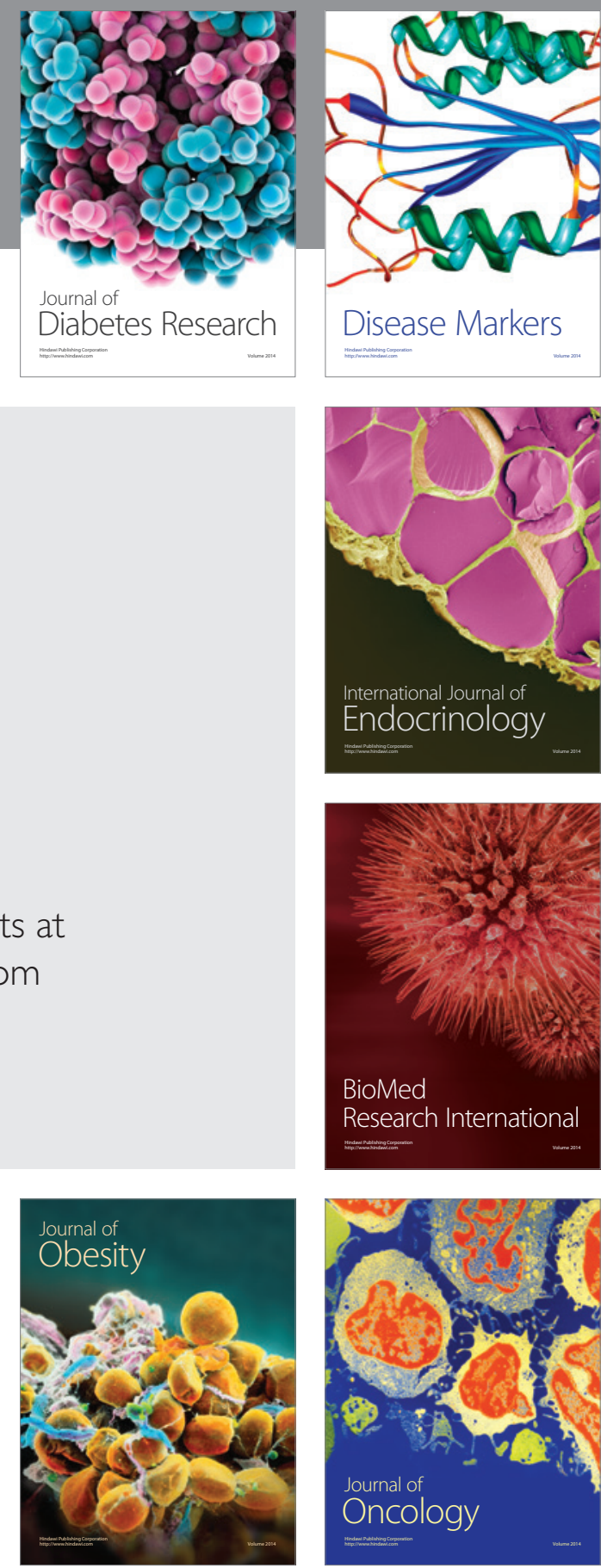

Disease Markers
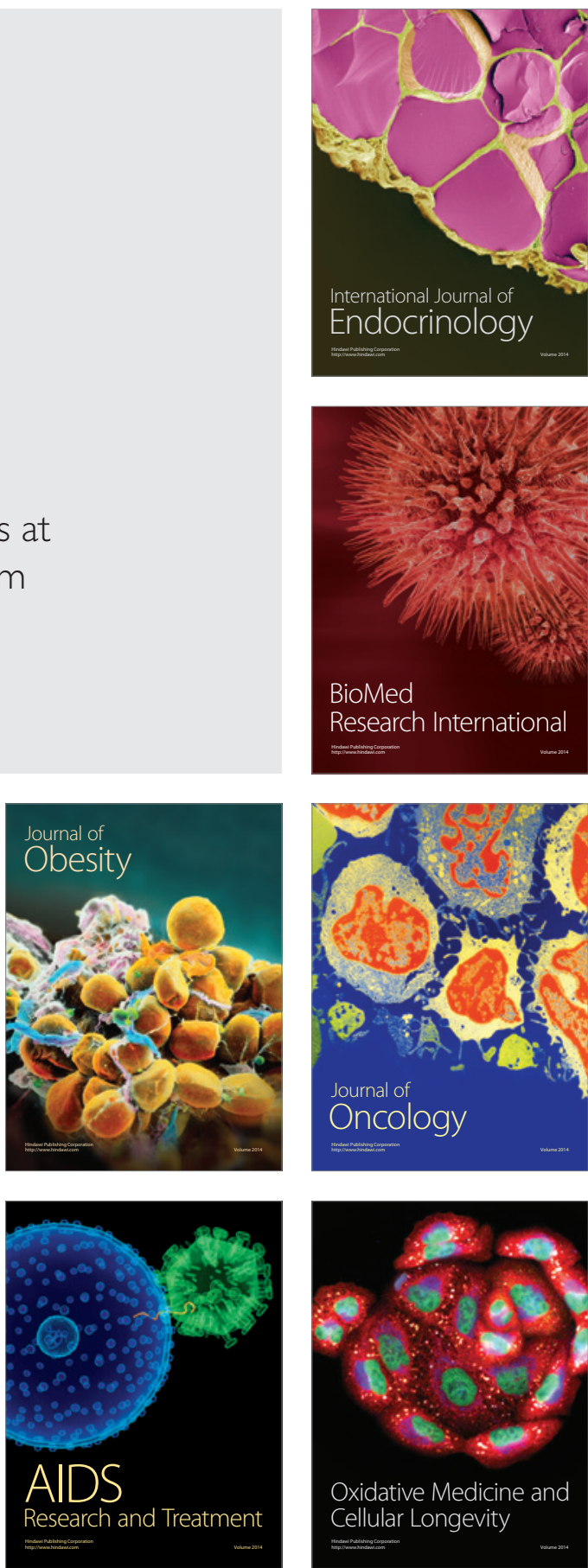